\title{
Evaluation of Visual Comfort and Mental Effort Under Different Light Conditions for Ultraviolet-Absorbing and Additional Blue-Filtering Intraocular Lenses for Cataract Surgery
}

\section{Visueller Komfort und mentale Anstrengung bei unterschiedlichem Umgebungslicht nach Kataraktoperation mit ultraviolett- versus zusätzlich blaufiltrierenden Intraokularlinsen}

Authors

Alexandra Steinemann ${ }^{1}$, Vivien Bromundt ${ }^{2}$, Sarah L. Chellappa ${ }^{3}$, Sylvia Frey ${ }^{4}$, Christina Schmidt ${ }^{5}$, Torsten Schlote ${ }^{6}$, David Goldblum ${ }^{1}$, Christian Cajochen ${ }^{4}$

\section{Affiliations}

1 Augenklinik, Universitätsspital Basel, Basel, Switzerland

2 Chronobiologie, Inselspital Universitätsspital Bern, Bern, Switzerland

3 Division of Sleep Medicine, Harvard Medical School, Boston, Massachusetts, United States

4 Chronobiologie, Universitätsspital Basel, Basel, Switzerland

5 GIGA-Research, Cyclotron Research Centre/In Vivo Imaging Unit, Université de Liège Département des Sciences de la Vie, Liège, Belgium

6 Ophthalmology, Tagesklinik Ambimed, Basel, Switzerland

Key words

cataract, visual comfort, mental effort, intraocular lens, blue filter

Schlüsselwörter

Katarakt, visual comfort, mental effort, Intraokularlinse, Blaufilter

received $\quad 11.10 .2018$

accepted 27.11.2018

Bibliography

DOI https://doi.org/10.1055/a-0810-0302

Published online 7.1.2019 | Klin Monatsbl Augenheilkd 2019; 236: 398-404 @ Georg Thieme Verlag KG Stuttgart .

New York | ISSN 0023-2165

Correspondence

Prof. David Goldblum

Universitätsspital Basel, Augenklinik

Mittlere Strasse 91, 4031 Basel, Switzerland

Phone: + 41612658686 , Fax: + 41612658743

david.goldblum@usb.ch

\section{ABSTRACT}

Patients and Methods Patients with an ultraviolet blocking lens (UV) $(n=5)$ or blue filter lens (BB) $(n=8)$ after intraocular lens $(\mathrm{IOL})$ replacement for cataract and age-adjusted controls (AACs) $(n=16)$ underwent a balanced crossover within-subject design. After $1.5 \mathrm{~h}$ of dark adaptation, they were exposed to polychromatic light at $6500 \mathrm{~K}$ (blue-enriched) and $2500 \mathrm{~K}$ and $3000 \mathrm{~K}$ (non-blue-enriched) for 2 hours in the evening. Visual comfort and mental effort were repeatedly assessed by the Visual Analogue Scale (0-100) and the Visual Comfort and Mental Effort Rating Scale (0-100) for each light condition. The results were compared using mixed model analysis.

Results The mean ( \pm SD) age for AAC and patients with UV or BB was $69.8 \pm 6.2 \mathrm{y}, 70.8 \pm 4 \mathrm{y}$, and $63.6 \pm 5.6 \mathrm{y}$, respectively. Irrespective of the light condition, patients with UV and BB felt mentally more tired during the experiments compared to AACs $(F=6.15, P=0.003)$. However, patients with BB were mentally more motivated to perform the exercises compared to patients with UV and AACs $(F=8.1, p<0.001)$. Patients with $B B$ perceived ambient light as less glary $(F=4.71$, $p=0.01)$ than patients with UV. Blue ambient light was felt less intensely in patients with $B B(F=2.51, p=0.042)$ compared to those with UV and the AACs.

Conclusion Lens replacement in older cataract patients may increase visual comfort and minimize mental effort. While subtle, the magnitude of these effects may depend on the type of intraocular lens. BB intraocular lenses may have potential benefits, as ambient light is perceived as having less glare and less visual tension.

\section{ZUSAMMENFASSUNG}

Hintergrund Bei schwierigen Lichtverhältnissen ist der visuelle Komfort beeinträchtigt und die mentale Anstrengung beim Sehen erhöht; besonders gilt dies für Kataraktpatienten. Unterschiedliche Intraokularlinsen stehen bei der Kataraktoperation zur Verfügung: die regulären ultraviolettblockie- 
renden (UV) und Intraokularlinsen mit zusätzlichem Blaufilter (BB). Die intrinsischen photosensitiven retinalen Zellen sind hochsensitiv für blaues Licht. Blaues Licht beeinflusst daher die visuelle Funktion. Das Ziel der Studie war der Vergleich des visuellen Komforts und der mentalen Anstrengung bei Patienten mit UV gegenüber solchen mit BB im Vergleich zu einer altersadaptierten Kontrollgruppe (AAC).

Patienten und Methoden Patienten mit AAC $(n=16)$ sowie UV $(n=5)$ und BB $(n=8)$ nach Kataraktoperation wurden in eine ausgewogene Cross-over-Studie eingeschlossen. Nach 1,5 h Dunkeladaption erfolgte im Labor die Exposition für $2 \mathrm{~h}$ bei blau angereichertem polychromatischem Umgebungslicht bei $6500 \mathrm{~K}$ (Kandula), nicht blau angereichertem Licht bei 2500 bzw. 3000 K. Für jedes Umgebungslicht wurde bei jeder Testserie erneut der Fragebogen zum visuellen Komfort und der mentalen Anstrengung (Visual Comfort und Mental Effort Rating Scale) ausgefüllt. Die Antworten wurden jeweils auf einer visuellen Analogskala von 0-100 eingetragen. Die statische Auswertung erfolgte mittels Mixed-Model-Analyse.
Ergebnisse Das mittlere Alter von AAC und Patienten mit UV oder BB war 69,8 $\pm 6,2,70,8 \pm 4,63,6 \pm 5,6$ Jahre. Unabhängig vom Umgebungslicht empfanden Patienten mit UV und BB die Tests als ermüdender im Vergleich zu den Patienten mit AAC $(F=6,15, P=0,003)$. Die Patienten mit BB waren motivierter, die Tests durchzuführen, bei blau angereichertem Umgebungslicht im Vergleich zu den Patienten mit UV und AAC $(F=8,1, p<0,001)$. Patienten mit BB haben die Umgebungslichter als weniger blendend wahrgenommen als die Patienten mit UV $(F=4,71, P=0,01)$. Blau angereichertes Umgebungslicht wurde als weniger nervös machend wahrgenommen bei Patienten mit $B B(F=2,51, P=0,042)$ verglichen mit Patienten mit UV und AAC.

Schlussfolgerung Obwohl der visuelle Komfort und die mentale Anstrengung zwischen BB und UV in den meisten Aspekten vergleichbar ist, unterscheiden sich die Patientengruppen in ausgewählten Aspekten. BB sind möglicherweise vorteilhaft, da das Umgebungslicht als weniger blendend empfunden wird und weniger mentale Anspannung für das Sehen erforderlich ist.

\section{Introduction}

Typically, the transparent crystalline lens develops bilateral hardening and clouding during normal aging. This compromises visual acuity and contrast sensitivity as well as glare sensation. The prevalence of age-related cataract affects approximately $75 \%$ of the population above 85 years old [1].

The common therapy of advanced cataract consists of the removal of the accumulated yellow chromophore lens and implantation of an artificial intraocular lens (IOL). Different kinds of lens replacements exist, such as monofocal, aspheric, or multifocal. Early IOL replacements did not filter a specific light wavelength until Ham et al. postulated retinal damage due to overexposure of ultraviolet light [2]. Ratnayake et al. investigated the mechanisms of phototoxity and subsequent retinal damage caused by blue light [3]. It is, however, known that the cornea and the natural lens absorb wavelengths below $300 \mathrm{~nm}$. Wavelengths between 300 and $400 \mathrm{~nm}$ are absorbed by the iris, but pass the pupillary aperture and the lens [4]. Thus, to optimize the function of aged lenses, IOL replacements with ultraviolet filtering and additional blue filters were constructed [5].

The adult crystalline lens blocks ultraviolet radiation about 300-400 nm [6]. The age-related change of the natural crystalline lens leads to a progressive reduction of the transmission in the blue range of the visible light [7]. The ultraviolet blocking lens (UV) reduces the blue-light irradiance by $60 \%$ compared to aphakic eyes. The blue filter lens (BB) blocks an additional 17$56 \%$ compared to the UV, depending on the type of implanted $\mathrm{IOL}$ and the diopter of the IOL [5]. The blue light transmission rate was down or below $25 \%$ in a 75 -year-old and was around $70 \%$ in a 53-year-old human crystalline lens, which corresponds to the transmission rate of the $\mathrm{BB}$ [8].

After IOL replacement for a cataract, more light is transmitted to the retina. This leads to better visual acuity, scotopic vision, and contrast vision. Although the benefits and side effects of blue filters are ultimately not clarified, it is assumed that blue filters compared to UV blocking reduce damage or progression of agerelated macular degeneration [9]. On the other side, the blue portion of the visible light spectrum is beneficial for regulating human sleep-wake cycles and circadian rhythms, particularly in older people. Thus, it is not clear whether a BB may negatively impact visual quality, scotopic vision, and circadian sleep-wake regulation in older cataract patients.

While targeted interventions for restoring optimal spectral transmittance include the implantation of artificial IOLs during cataract surgery, it remains to be fully established whether the beneficial effects of cataract IOLs translate to changes in visual comfort and mental effort during light exposure. Here, it was investigated whether IOL replacement [blue blocking (BB) or UV only blocking, (UV)] in older cataract patients improves visual comfort and mental effort, as compared to age-matched healthy older adults.

\section{Patients and Methods}

The protocol and questionnaires were approved by the ethical committee of Northwest and Central Switzerland and were in accordance with the Declaration of Helsinki. All patients gave their informed consent.

Patients were recruited at the eye clinic of the University Hospital Basel, Switzerland, and the Ambimed Basel Clinic, Switzerland. Patients aged between 55-80 years of age, with age-related cataracts requiring bilateral cataract surgery and a minimum of +18 diopter and a maximum of +26 diopters for the IOL were included. Further inclusion criteria were a body mass index between 18 and $28 \mathrm{~kg} / \mathrm{m}^{2}$, and stable medication for the past 2 months before surgery and throughout the study duration. Patients with coexisting ocular pathologies, systemic diseases of somatic origin, 
psychiatric disorders (ongoing or within the past 2 years), prior history of shift work within 3 months, transmeridian travel within the last month, participation in other clinical trials within 3 months before the start of the study, sleep disorders, or drug or alcohol abuse were excluded. Furthermore, patients who used antihypertensives, nonsteroidal anti-inflammatory drugs (including aspirin), benzodiazepines, or hormone replacement therapy were excluded. Based on medical records, patients were screened for exclusion criteria. Biochemical blood screening tests and physical examinations were performed. The Mini-Mental State Examination excluded disorders with a neurocognitive function. A toxicological screening for drug, smoking, and alcohol abuse was performed.

All patients underwent an eye examination, including visual acuity measurement in decimal values, intraocular pressure measurement with a noncontact air-puff tonometer or Goldmann applanation tonometer, and split lamp examination of anterior and posterior segments of the eyeballs. The fundus was examined under dilated pupils. The lenses of the control groups were staged according to the Lens Opacities Classification System III (LOCS III) [10].

All participants in the UV and BB groups went through bilateral IOL replacement performed by two experienced surgeons. BB IOLs were implanted by one of these surgeons (D. G.), while UV IOLs were implanted by the other surgeon (T.S.). They were performed using standard techniques through a limbal or clear corneal incision, implanting a UV (SA60 WF IOL; Alcon, Switzerland) or a BB (SN60 WF IOL; Alcon, Switzerland). Standard postoperative local medication using dexamethasone und tobramycin eye drops for a minimum of 3 weeks was prescribed. Second eye phacoemulsification and IOL implantation were performed using the same implant as in the first eye within 4-6 weeks of the first cataract surgery.

At the earliest, 4-8 weeks after IOL replacement of the second eye, the pseudophakic patients as well as the age-adjusted control (AAC) group underwent a stringently controlled, randomized, within-subject crossover design. The participants had to spend three nights at the laboratory. During the study, the participants remained in an individual laboratory room. In the laboratory environment, all external environmental light effects were avoided, and the room was uniformly painted with high reflective white painting. A compact fluorescent light source with a highly correlated color temperature (6500 K, Osram Duluxstar Mini Twist, Lumilux, cool daylight, France) was compared with a similar light source with a lower color temperature (2500 K, Osram Duluxstar Mini Twist, Lumilux, warm comfort light) and an incandescent light source with a color temperature of $3000 \mathrm{~K}$ (Osram incandescent lamp Classic A). Light was homogenously distributed within the visual field. Therefore, the whole room acted almost like an integrating sphere.

At beginning of the investigation, the participants underwent a first period of $1.5 \mathrm{~h}$ under dim light conditions ( $<8$ lux), which was followed by a 2-h dark adaptation (0 lux). Next, the participants were exposed to either blue-enriched $(6500 \mathrm{~K})$ or nonblue-enriched light ( $3000 \mathrm{~K}$ and $2500 \mathrm{~K}$ ) for $2 \mathrm{~h}$, followed by a 30 min postexposure episode in dim light. Each participant underwent all three light treatments in a balanced crossover design while filling in the Visual Comfort Scale [11] and Mental Effort Rating Scale [12] in regular time intervals. The questionnaires comprised visual analogue scales $(0-100 \mathrm{~mm})$ and were statistically analyzed by mixed model analysis [13-15].

Statistical analyses were performed using SAS (version 9.1; SAS Institute, Cary, NC). Data analyses of the Visual Comfort and Mental Effort Rating Scale were compared using the mixed model analyses of variance for repeated measures (PROC MIXED) using within-subject factors "item of questionnaire" (once during each light condition) and "light condition" (6500 K vs. $2500 \mathrm{~K}$ vs. $3000 \mathrm{~K}$ ), and between-subject factor "group" (controls, UV and BB replacement post-cataract surgery patients), as well as the 3way interaction with "light condition" vs. "group" vs. "item of questionnaire".

All p values were based on Kenward-Rogers corrected degrees of freedom (significance level: $p<0.05$ ). The least square means statement was used for post hocs, and the Tukey-Kramer test was then used for the correction of multiple comparisons on the continuous time-series data.

\section{Results}

Twenty-nine older participants were enrolled in this study, out of which 16 were AAC individuals (age range: $55-80$ years; mean + SD: $63.6 \pm 5.6$ y; 8 women) and 13 were age-matched post-cataract patients (age range, 55-80 years; mean + SD: 69.9 \pm 5.2 y; 10 women). These 13 patients underwent bilateral phacoemulsification with IOL implantation with BB ( $n=8$; mean age + SD: $69.8 \pm$ $6.2 \mathrm{y} ; 7$ women) or UV ( $\mathrm{n}=5$; mean age + SD: $70.8 \pm 4 \mathrm{y} ; 4$ women).

In the AAC group, an ophthalmologic examination demonstrated an intraocular pressure range between 11 to $19 \mathrm{mmHg}$ and a median visual acuity of 1.0 (range: $0.6-1.0$ ) for each eye. In three patients, a pseudo-exfoliation without further pathology of the optic nerve or eye pressure was found. One patient showed a minor corneal scar and another patient suffered from mild amblyopia, with a visual acuity in this eye of 0.63 . Median LOCS III of the right eye was 2 for nuclear opalescence (range 1-2.9), 2 for nuclear color (range 0-2.9), 0 for cortical cataract (range 0-3.5), and 0 for posterior subcapsular cataract (range $0-1$ ). Median LOCS III of the left eye was 2 for nuclear opalescence (range 12.5), 2 for nuclear color (range 0-2.8), 0 for cortical cataract (range 0-3.6), and 0 for posterior subcapsular cataract (range 0 1). In the group of participants with UV, no noticeable findings in the split lamp examination were observed. The intraocular pressure ranged from 13 to $20 \mathrm{mmHg}$, the median visual acuity of the right pseudophakic eye was 1.0 (range: $0.63-1.0$ ) and the left pseudophakic eye was 1.0 (range: $0.8-1.0$ ). In the group of patients with BB, fundoscopy showed one eye with glaucomatous suspicious excavation of the optic nerve without glaucomatous visual field defects. The intraocular pressure ranged from 10 to $17 \mathrm{mmHg}$, the median visual acuity of the right eye was 0.9 (range: 0.63-1.0) and the left eye was 1.0 (range: 0.8-1.0).

With respect to mental effort, UV and BB patients had significantly higher levels of mental tiredness compared to ACCs (main effect "group"; $F=6.15, p=0.003$ ), irrespective of the light situation. However, BB patients had significantly higher levels of moti- 
- Table 1 Differences in the Visual Comfort Scale for groups (ACCs, UV, BB) and light conditions (blue, classic, warm). *Significant differences.

\begin{tabular}{|c|c|}
\hline & $\begin{array}{l}\text { Group (ACCs, UV, BB) } \\
\text { Light Condition (blue, classic, warm) versus Group }\end{array}$ \\
\hline I can read well on the screen. & $\begin{array}{l}\text { Group: } F=2.01, p=0.135 \\
\text { Light Condition }- \text { Group: } F=1.99, p=0.0953\end{array}$ \\
\hline I see reflections on the screen. & $\begin{array}{l}\text { Group: } F=1.22, p=0.296 \\
\text { Light Condition }- \text { Group: } F=1.01, p=0.402\end{array}$ \\
\hline $\begin{array}{l}\text { I see no disturbing/interfering pattern } \\
\text { on the screen. }\end{array}$ & $\begin{array}{l}\text { Group: } F=1.35, p=0.262 \\
\text { Light Condition - Group: } F=1.67, p=0.156\end{array}$ \\
\hline The ambient light condition bothers me. & $\begin{array}{l}\text { Group: } F=2.60, p=0.075 \\
\text { Light Condition }- \text { Group: } F=2.51, p=0.042^{*} \\
\text { Blue ambient light was felt less tense in patients with BB compared to AACs and patients with UV. }\end{array}$ \\
\hline The ambient light condition is comfortable. & $\begin{array}{l}\text { Group: } F=1.61, p=0.201 \\
\text { Light Condition Group: } F=1.66, p=0.159\end{array}$ \\
\hline The artificial light is not glaring. & $\begin{array}{l}\text { Group: } F=4.71, p=0.01^{*} \\
\text { Patients with } B B \text { perceived ambient light as having less glare than patients with UV. } \\
\text { Light Condition - Group: } F=0.36, p=0.835\end{array}$ \\
\hline The artificial light is too dark. & $\begin{array}{l}\text { Group: } F=0.70, p=0.496 \\
\text { Light Condition }- \text { Group: } F=1.20, p=0.308\end{array}$ \\
\hline
\end{tabular}

- Table 2 Differences in the Mental Effort Rating Scale for groups (ACCs, UV, BB) and light conditions (blue, classic, warm). *Significant differences.

\begin{tabular}{|c|c|}
\hline & $\begin{array}{l}\text { Group effect (ACCs, UV, BB) } \\
\text { Light condition effect (blue, classic, warm) versus Group }\end{array}$ \\
\hline $\begin{array}{l}\text { How much did you have to exert yourself } \\
\text { during the last tests until the break? }\end{array}$ & $\begin{array}{l}\text { Group: } F=1.44, p=0.239 \\
\text { Light Condition - Group: } F=0.20, p=0.941\end{array}$ \\
\hline How strong did you had to concentrate yourself? & $\begin{array}{l}\text { Group: } F=0.64, p=0.530 \\
\text { Light Condition }- \text { Group: } F=0.65, p=0.627\end{array}$ \\
\hline How exhausting did you experience the tests? & $\begin{array}{l}\text { Group: } \mathrm{F}=6.15, \mathrm{p}=0.003 \\
\text { Pseudophakic patients felt mentally more tired during the experiments compared to ACCs, } \\
\text { irrespective of the light condition } \\
\text { Light Condition - Group: } F=0.80, p=0.529\end{array}$ \\
\hline How motivated did you feel to perform the tests? & $\begin{array}{l}\text { Group: } F=8.1, p<0.001 \\
\text { Patients with a } B B \text { IOL were mentally more motivated to perform the exercises compared } \\
\text { to patients with a UV IOL and the } A C C s \text {. } \\
\text { Light Condition - Group: } F=1.44, p=0.223\end{array}$ \\
\hline $\begin{array}{l}\text { In comparison to preceding tests, did it take } \\
\text { you more or less effort now? }\end{array}$ & $\begin{array}{l}\text { Group: } F=2.82, p=0.064 \\
\text { Light Condition }- \text { Group: } F=1.42, p=0.230\end{array}$ \\
\hline
\end{tabular}

vation compared to UV patients and the ACC group (main effect "group"; $F=8.1, p<0.001$ ). With respect to visual comfort, BB patients had significantly lower levels of perceived ambient light glare compared to UV patients and the ACC group (main effect "group"; $F=4.71, p=0.01$ ). Importantly, the interaction of "light condition" vs. "group" yielded a significant effect, such that BB patients had lower levels of visual tension when exposed to blueenriched ambient light compared to UV patients and the ACC group (multiple comparison adjustment; $F=2.51, \quad P=0.042$ ) ( $\triangleright$ Tables 1 and 2, Fig. 1).

\section{Discussion}

Lens replacement in older cataract patients may increase visual comfort and minimize mental effort. The findings of the present study indicate that, while subtle, the magnitude of these effects may depend on the type of intraocular lens. A BB intraocular lens might have potential benefits, as ambient light is perceived as having less glare and less visual tension.

The crystalline lens in young adults has a very high absorption of the blue spectrum of light [16]. Removal of the natural lens leads to a dramatic increase in retinal illumination. Yet, filtering with a BB IOL still increases scotopic illumination by $52 \%$ in the young phakic eye, while filtering with an UV IOL leads to an even more pronounced increase in scotopic illumination [17]. Thus, a 


\section{Visual Comfort Scale}
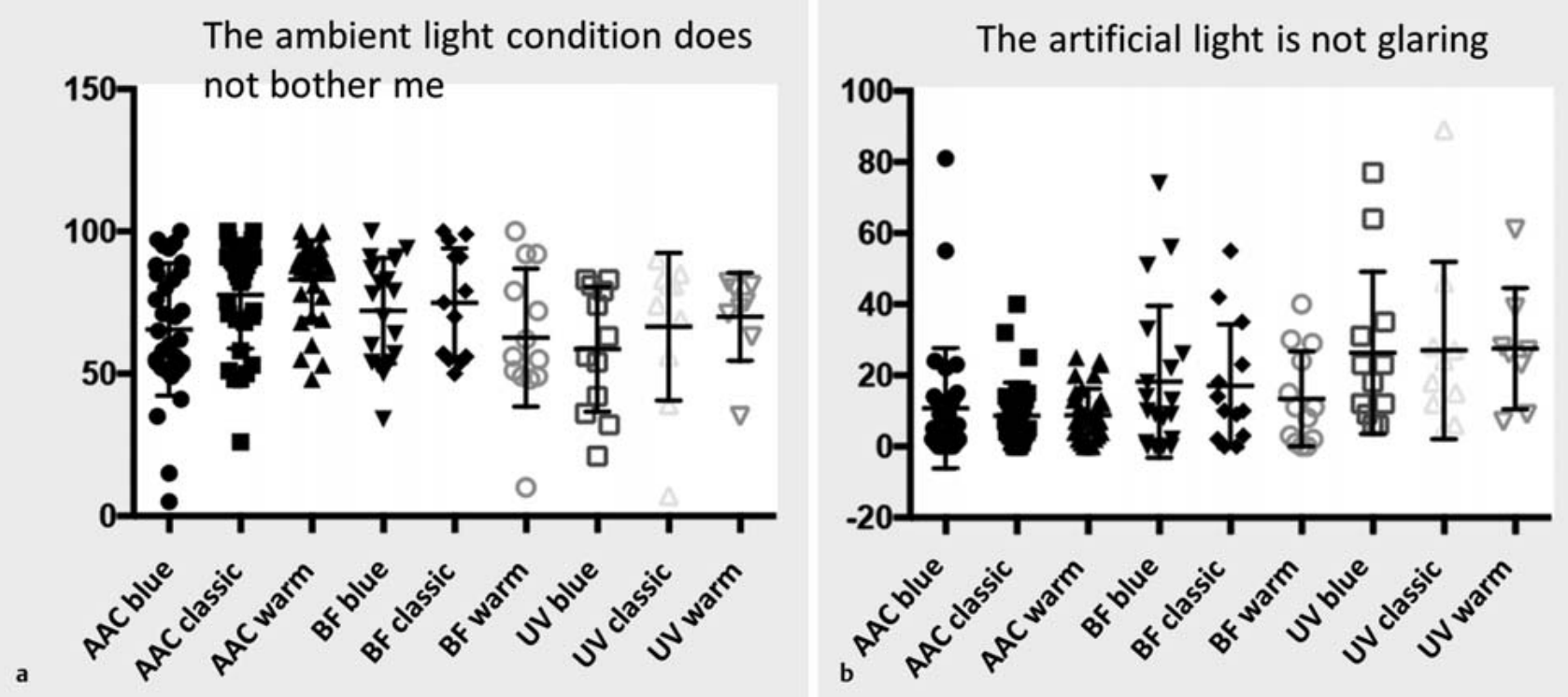

\section{Mental Effort Rating Scale}
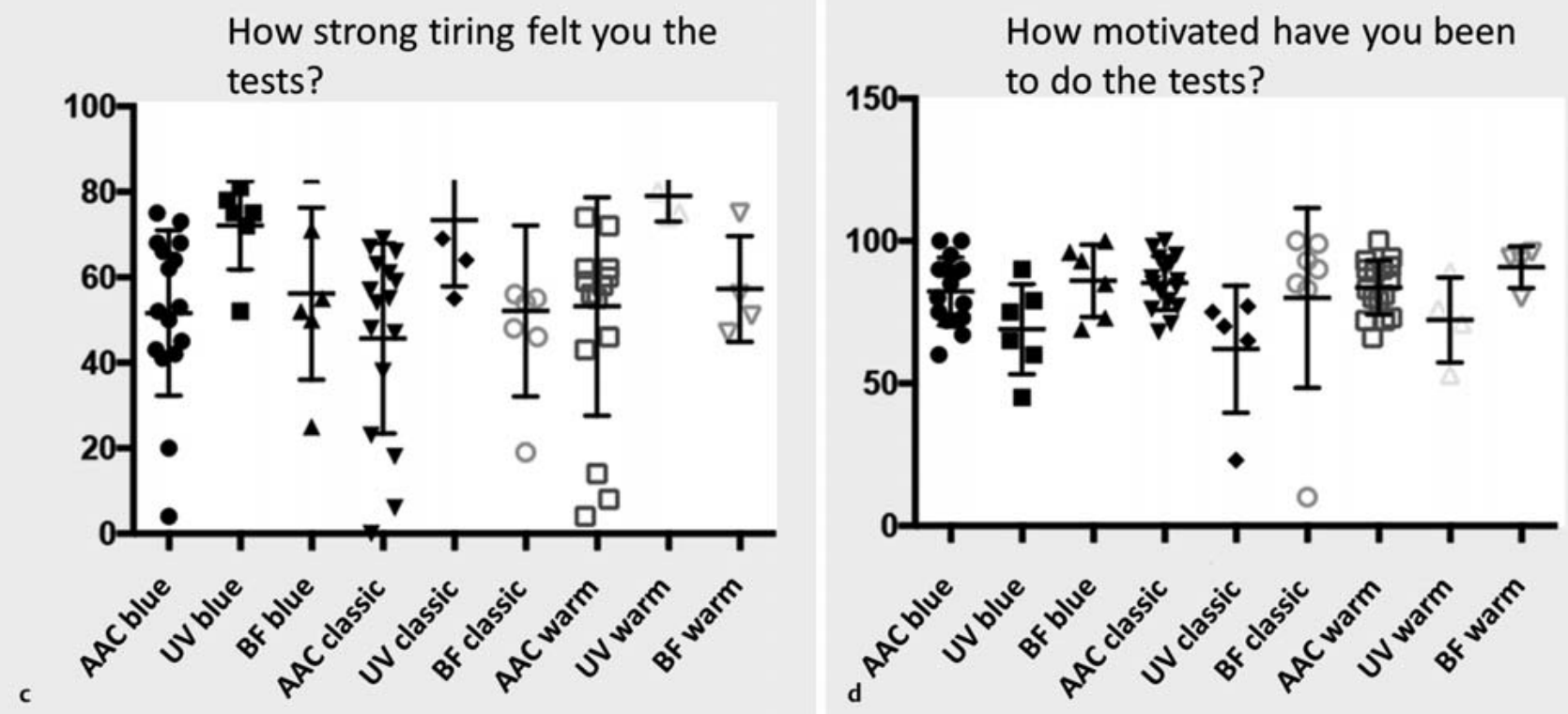

- Fig. 1 a Blue ambient light was felt less tense in patients with a blue-filtering intraocular lens (BB) compared to age-adjusted controls (AACs) and patients with an ultraviolet-filtering intraocular lens (UV) $(F=2.51, p=0.042)$; $b$ Patients with BB perceived ambient light as having less glare than patients with UV $(F=4.71, p=0.01)$; $c$ Pseudophakic patients felt mentally more tired during the experiments compared to the AAC group, irrespective of the light condition $(F=6.15, p=0.003)$; $d$ Patients with $B B$ were mentally more motivated to perform the exercises compared to UV and $\operatorname{AACs}(F=8.1, p<0.001)$

BB IOL might mimic the young natural lens better than UV alone. Moreover, there is increasing evidence of nonimaging forming effects of light mediated by intrinsically photosensitive ganglion cells in the retina (ipRGCs), which express the photopigment melanopsin. Nonimage forming responses to light comprise effects on circadian rhythms and sleep, as well as also on human 
alertness [18]. Interestingly, melanopsin is maximally sensitive to short wavelength light in the blue spectrum $(\sim 480 \mathrm{~nm})$, which may play a role in modulating changes in mental effort.

Potential visual and nonvisual benefits of BB compared to standard UV have been a matter of debate for the last 25 years. The comparison of visual performance and visual comfort in UV versus BB patients shows conflicting findings.

Neumaier-Ammerer et al. found that a BB was equivalent to a UV in terms of contrast sensitivity, visual acuity, and color perception under photopic conditions. However, patients with a BB made more mistakes in the blue range under dim light conditions 1 week to 2 months after surgery [19]. Furthermore, Pierre et al. found that the BB affected the perception of luminance under photopic conditions. The requirement for blue light for luminance judgement was increased when a BB was used compared to a UV [20]. Schmack et al. found a BB and UV had similar postoperative visual functions, except for color perception, which was slightly better in patients with a UV compared to BB by follow-ups at 1, 3, and 6 months after surgery [21]. In contrast to the findings of the current study, Hayashi and Hayashi found no difference between patients with UV and BB for contrast visual acuity or glare visual acuity under photopic or higher luminance mesopic conditions. In patients with a BB scotopic sensitivity, however, was reduced by 15 to $21 \%$ and color vision was compromised in the blue light spectrum under mesopic light conditions [21,22]. In the long-term, Kara-Junior et al. found no difference between patients with BB and UV in color perception and scotopic or photopic contrast sensitivity 5 years after surgery [23]. As a short-term benefit, the symptom cyanopsia, which was reported by $14 \%$ of patients after IOL replacement with UV lenses, was not observed in BB patients. After 3 months, however, cyanopsia also resolved in BB also [24]. In addition to these results, the current study reveals less glare sensation and less tension in a blue-enriched light environment in BB patients compared to UV patients 1 to 2 months after surgery.

The difference between UV and BB (based on spectral lens transmission) at $505 \mathrm{~nm}$ (peak for rod wavelength sensitivity) and $550 \mathrm{~nm}$ (peak for M-cone sensitivity) is 10 and $5 \%$ respectively. That difference may not be sufficient to detect group effects for these wavelengths. Perhaps with other types of BB lens, which block wavelengths stronger these (particularly around $500 \mathrm{~nm}$ ), such group effects would have been detected. Further, light effects on the aging are more noticeable at the photopic sensitivity range and when individuals are exposed to higher irradiance in the blue wavelength range [25], which may partially explain the nonsignificant effects in the current study. Additionally, objective tests to measure contrast sensitivity may be more sensitive compared to subjective scales of light perception and visual comfort. However, the benefit of using visual analogue scales (as in the present study) is that they provide an immediate and repeatable measure on mental effort and visual comfort, thus estimating how these patients perceive light and the effort they need to solve the tasks.

Considering the modern lifestyle with increasing blue light exposure, the question on the ideal IOL replacement model remains highly relevant. Yet, the effects of UV and additional BB on visual acuity and comfort still remain ambiguous. The present study demonstrated differences towards a subjective optimized visual comfort when BBs were used.

\section{Conflict of Interest}

The authors declare no conflict of interest.

\section{References}

[1] Song P, Wang $\mathrm{H}$, Theodoratou $\mathrm{E}$ et al. The national and subnational prevalence of cataract and cataract blindness in China: a systematic review and meta-analysis. J Glob Health 2018; 8: 010804. doi:10.7189/jogh. 08-010804

[2] Ham WT jr., Mueller HA, Sliney DH. Retinal sensitivity to damage from short wavelength light. Nature 1976; 260: 153-155

[3] Ratnayake K, Payton JL, Lakmal OH et al. Blue light excited retinal intercepts cellular signaling. Sci Rep 2018; 8: 10207. doi:10.1038/s41598018-28254-8

[4] Wittenberg S. Solar radiation and the eye: a review of knowledge relevant to eye care. Am J Optom Physiol Opt 1986; 63: 676-689

[5] Tanito M, Okuno T, Ishiba $Y$ et al. Transmission spectrums and retinal blue-light irradiance values of untinted and yellow-tinted intraocular lenses. J Cataract Refract Surg 2010; 36: 299-307. doi:10.1016/j. jcrs.2009.08.036

[6] Norren DV, Vos JJ. Spectral transmission of the human ocular media. Vision Res 1974; 14: 1237-1244

[7] Weale RA. Age and the transmittance of the human crystalline lens. J Physiol 1988; 395: 577-587

[8] Brockmann C, Schulz M, Laube T. Transmittance characteristics of ultraviolet and blue-light-filtering intraocular lenses. J Cataract Refract Surg 2008; 34: 1161-1166. doi:10.1016/j.jcrs.2008.03.039

[9] Kessler RC, Berglund PA, Coulouvrat $C$ et al. Insomnia and the performance of US workers: results from the America insomnia survey. Sleep 2011; 34: 1161-1171. doi:10.5665/SLEEP.1230

[10] Chylack LT jr., Wolfe JK, Singer DM et al. The Lens Opacities Classification System III. The longitudinal Study of Cataract Study Group. Arch Ophthalmol 1993; 111: 831-836

[11] Boyce PR. Lighting research for interiors: the beginning of the end or the end of the beginning. Light Res Technol 2004; 36: 283-293

[12] Verwey WB, Veltman HA. Detecting short periods of elevated workload: comparison of nine assessment techniques. J Appl Psychol Applied 1996; 2: $270-285$

[13] Chellappa SL, Steiner R, Blattner $P$ et al. Non-visual effects of light on melatonin, alertness and cognitive performance: can blue-enriched light keep us alert? PLoS One 2011; 6: e16429. doi:10.1371/journal.pone. 0016429

[14] Chellappa SL, Viola AU, Schmidt C et al. Human melatonin and alerting response to blue-enriched light depend on a polymorphism in the clock gene PER3. J Clin Endocrinol Metab 2012; 97: E433-E437. doi:10.1210/ jc.2011-2391

[15] Chellappa SL, Viola AU, Schmidt $C$ et al. Light modulation of human sleep depends on a polymorphism in the clock gene Period3. Behav Brain Res 2014; 271: 23-29. doi:10.1016/j.bbr.2014.05.050

[16] Artigas JM, Felipe A, Navea A et al. Spectral transmission of the human crystalline lens in adult and elderly persons: color and total transmission of visible light. Invest Ophthalmol Vis Sci 2012; 53: 4076-4084. doi:10.1167/iovs.12-9471

[17] Schwiegerling J. Blue light-filtering intraocular lenses and scotopic sensitivity. J Cataract Refract Surg 2009; 35: 2032; author reply 2032. doi:10.1016/j.jcrs.2009.07.005 
[18] Chellappa SL, Gordijn MC, Cajochen C. Can light make us bright? Effects of light on cognition and sleep. Prog Brain Res 2011; 190: 119-133. doi:10.1016/B978-0-444-53817-8.00007-4

[19] Neumaier-Ammerer B, Felke S, Hagen $S$ et al. Comparison of visual performance with blue light-filtering and ultraviolet light-filtering intraocular lenses. J Cataract Refract Surg 2010; 36: 2073-2079. doi:10.1016/j. jcrs.2010.06.069

[20] Pierre A, Wittich W, Faubert J et al. Luminance contrast with clear and yellow-tinted intraocular lenses. J Cataract Refract Surg 2007; 33 : 1248-1252. doi:10.1016/j.jcrs.2007.03.024

[21] Schmack I, Schimpf M, Stolzenberg A et al. Visual quality assessment in patients with orange-tinted blue light-filtering and clear ultraviolet lightfiltering intraocular lenses. J Cataract Refract Surg 2012; 38: 823-832. doi:10.1016/j.jcrs.2011.12.028
[22] Zhu XF, Zou HD, Yu YF et al. Comparison of blue light-filtering IOLs and UV light-filtering IOLs for cataract surgery: a meta-analysis. PLoS One 2012; 7: e33013. doi:10.1371/journal.pone.0033013

[23] Kara-Junior N, Espindola RF, Gomes BA et al. Effects of blue light-filtering intraocular lenses on the macula, contrast sensitivity, and color vision after a long-term follow-up. J Cataract Refract Surg 2011; 37: 21152119. doi:10.1016/j.jcrs.2011.06.024

[24] Hayashi K, Hayashi H. Visual function in patients with yellow tinted intraocular lenses compared with vision in patients with non-tinted intraocular lenses. Br J Ophthalmol 2006; 90: 1019-1023. doi:10.1136/ bjo.2006.090712

[25] Daneault V, Hebert M, Albouy G et al. Aging reduces the stimulating effect of blue light on cognitive brain functions. Sleep 2014; 37: 85-96. doi:10.5665/sleep.3314 